\title{
Quality of Life Perempuan Penyintas Kekerasan Seksual: Studi Kualitatif
}

\author{
Abdul Muhid1, Lia Masfiatul Khariroh', Nailatin Fauziyah1, Funsu Andiarna1 \\ 1) Fakultas Psikologi dan Kesehatan UIN Sunan Ampel, Surabaya, Indonesia \\ abdulmuhid@uinsby.ac.id \\ DOI: http://doi.org/10.29080/jhsp.v3i1.185
}

\begin{tabular}{|c|c|}
\hline Kata Kunci & Abstrak \\
\hline $\begin{array}{l}\text { Quality of life, } \\
\text { Perempuan } \\
\text { penyintas, } \\
\text { Kekerasan } \\
\text { seksual }\end{array}$ & $\begin{array}{l}\text { Penelitian ini bertujuan untuk mengungkap bagaimana keadaan quality of life } \\
\text { perempuan penyintas kekerasan seksual. Penelitian ini menggunakan pendekatan } \\
\text { kualitatif dengan jenis penelitian studi kasus. Subyek penelitian ini adalah remaja } \\
\text { perempuan penyintas kekerasan seksual peserta dampingan program kegiatan support } \\
\text { group yang dilakukan oleh lembaga Women's Crisis Center (WCC) Jombang. Secara } \\
\text { umum temuan penelitian ini menujukkan bahwa para penyintas memiliki quality of life } \\
\text { yang baik, hal itu ditunjukan dengan adanya penerimaan diri yang positif. Di samping itu } \\
\text { para penyintas merasa telah berkurang rasa kecewa, sudah mulai dapat melupakan } \\
\text { masa lalu, sudah mampu mengelola emosi, tidak merasa malu karena pernah menjadi } \\
\text { korban kekerasan seksual, serta mulai memiliki keyakinan untuk bisa menjadi pribadi } \\
\text { yang lebih baik dibandingkan dengan masa lalunya. Penyintas sudah mulai menerima } \\
\text { dirinya yang sekarang, meski berbeda dengan perempuan remaja sebayanya yang bebas } \\
\text { bersekolah dan bermain. Penyintas mampu menerima diri untuk mengurus anak dan } \\
\text { menjalani tanggung jawab sebagai seorang ibu. Dengan dukungan sosial orang-orang } \\
\text { terdekat, para penyintas yakin mampu menjalani hidup dengan lebih baik. }\end{array}$ \\
\hline Keywords & Abstract \\
\hline $\begin{array}{l}\text { Quality of life, } \\
\text { Survivor } \\
\text { woment, } \\
\text { Sexual violence }\end{array}$ & $\begin{array}{l}\text { This study aims to reveal how the quality of life of women survivors of sexual violence. } \\
\text { This study uses a qualitative approach with a type of case study research. The subjects of } \\
\text { this study were female adolescents who survived the sexual violence of the participants } \\
\text { assisted by the support group activity program conducted by the Jombang Women's Crisis } \\
\text { Center (WCC). In general, the findings of this study show that survivors have good quality } \\
\text { of life, this is indicated by positive self-acceptance. In addition, the survivors felt a sense of } \\
\text { disappointment, had begun to forget the past, had been able to manage emotions, did not } \\
\text { feel embarrassed because they had been victims of sexual violence, and began to have } \\
\text { confidence in being better than their past. Survivors have begun to accept themselves now, } \\
\text { even though they are different from their teenage girls who are free to go to school and } \\
\text { play. Survivors are able to accept themselves to take care of children and carry out } \\
\text { responsibilities as a mother. With the social support of the closest people, the survivors } \\
\text { believe they can live a better life }\end{array}$ \\
\hline
\end{tabular}

\section{Pendahuluan}

Kasus tindak kekerasan seksual yang dialami oleh perempuan di Indonesia setiap tahun mengalami peningkatan yang cukup signifikan (1). Korban tindak kekerasan seksual tersebut tidak hanya dialami oleh para perempuan dewasa saja, namun juga dialami oleh perempuan remaja, anak-anak bahkan balita (2). Kenyataan yang ada dalam masyarakat sekarang ini bahwa tindak kekerasan seksual pada perempuan tidak hanya dalam ranah privat, tetapi sudah tampak dalam ranah publik, mulai dari pelecehan seksual sampai pemerkosaan dan penghilangan nyawa pada korban (3). Seharusnya secara hukum para perempuan mendapatkan perlindungan dan hak-haknya, namun realitasnya berbanding terbalik para perempuan sangat rentan menjadi obyek kekerasan seksual (4). Hasil penelitian Dzuhayatin \& Yuarsi (2002) di empat provinsi di Indonesia yaitu Sumatera Utara, Yogyakarta, Sulawesi Selatan, dan Irian Jaya menunjukkan bahwa 90\% perempuan pernah mengalami kekerasan seksual di ranah publik (5).

Menurut Komisi Nasional Perempuan -sebagaimana dalam Catatan Tahunan (CATAHU)- pada tahun 2017 terjadi tindak kekerasan seksual di ranah domestik (privat) yang menunjukkan bahwa kasus pemerkosaan menempati posisi tertinggi sebanyak 1.389 kasus, diikuti kasus pencabulan sebanyak 1.266 
kasus, sedangkan di ranah publik di mana kekerasan seksual menempati peringkat pertama sebanyak 2.290 kasus, diikuti kekerasan fisik 490 kasus, dan kekerasan psikis 83 kasus, sedangkan di ranah komunitas kasus kekerasan seksual yang paling banyak adalah tindakan pemerkosaan pada perempuan sebanyak 1.036 kasus dan pencabulan sebanyak 838 kasus. Pada tahun 2018 Komisi Nasional Perempuan melaporkan bahwa tindak kekerasan seksual yang dialami perempuan mengalami peningkatan jumlah kasusnya. Di ranah domestik (privat) data menunjukkan tindak kekerasan seksual terhadap anak perempuan sebanyak 2.227 kasus, tindak kekerasan seksual terhadap istri sebanyak 5.167 kasus, dan tindak kekerasan seksual pada remaja perempuan sebanyak 1.873 kasus, sedangkan tindak kekerasan di ranah publik mencapai angka 3.528 kasus di mana kekerasan seksual menempati peringkat pertama sebanyak 2.670 kasus diikuti berturut-turut kekerasan fisik sebanyak 466 kasus, kekerasan psikis sebanyak 198 kasus, adapun tindak kekerasan seksual yang paling banyak di ranah komunitas adalah pencabulan sebanyak 911 kasus, pelecehan seksual sebanyak 708 kasus, dan tindak perkosaan sebanyak 669 kasus (6).

Peningkatan angka kasus kekerasan seksual yang menimpa perempuan tersebut diakibatkan oleh adanya budaya patriarki dan sikap permisif yang ada di masyarakat (1). Perempuan rentan mengalami tindak kekerasan seksual disebabkan oleh adanya tata nilai di masyarakat yang mendudukan perempuan pada posisi subordinasi, marginalisasi, dikuasai, dan dieksploitasi (5). Sedangkan menurut Sunarto \& Faiqoh (2013), persepsi masyarakat tentang adanya dominasi dan hegemoni kelompok laki-laki atas perempuan dapat menyuburkan hostile environment yang menjadi penyebab tindak kekerasan seksual kepada perempuan (7). Hal itu karena perempuan selalu dipandang sebagai second class citizens (3). Di mana habitus perempuan yang menempatkan sebagai makhluk kelas dua tersebut seringkali menjadi alasan adanya tindakan kekerasan seksual pada perempuan (8).

Kekerasan seksual telah menjadi perhatian serius oleh masyarakat dunia karena akibat yang ditumbulkan sangat berdampak terhadap kesehatan. Dampak kekerasan seksual memberikan resiko yang sangat besar bagi kesehatan fisik, psikis, mental, perilaku dan trauma psikis yang dapat berdampak tidak hanya kepada individu tetapi juga berdampak kepada keluarga dan masyarakat (9). Resiko fisik, psikis, dan sosial yang ditimbulkan akibat kekerasan seksual dapat berlangsung bertahun-tahun selama kehidupan si korban (10). Temuan Sisca, \& Moningka (2008) menunjukan bahwa dampak psikologis akibat tindak kekerasan seksual pada si korban adalah cenderung menyalahkan keadaan dan orang lain di sekitarnya sehingga sulit menerima masa lalunya (11). Perempuan yang menjadi korban tindak kejahatan seksual selain menanggung dampak psikologis dan kesehatan juga sering kali tidak mendapatkan keadilan di mata hokum (12). Di sisi yang lain, perempuan korban kekerasan seksual secara kesehatan rentan menderita berbagai penyakit (13).

Menurut hasil penelitian Chisholm, Bullock, \& Ferguson (2017), bahwa 40\% perempuan di Amerika Serikat menjadi korban kekerasan seksual mengalami gangguan kesehatan fisik dan mental (14). Dampak kesehatan fisik seperti patah tulang, liserasi dan trauma kepala, berbagai gangguan nyeri, penyakit infeksi seksual menular dan kehamilan yang tidak diinginkan. Dampak kesehatan mental termasuk peningkatan resiko depresi, kecemasan, gangguan pasca trauma, dan bunuh diri. Dampak-kesehatan yang paling merugikan adalah kehamilan dan resiko dampak iringan seperti kelahiran premature, berat badan lahir rendah dan kecil. Menurut Bell (2015) bahwa tindak kejahatan seksual termasuk kejahatan gnosida yang berdampak pada kematian, kehamilan dan penularan infeksi HIV/AIDS (15). Penelitian-penelitian lainnya menunjukkan hal yang sama bahwa perempuan yang mengalami tindak kejahatan seksual dialami oleh perempuan berdampak secara psikologis, sosial dan dampak kesehatan beresiko lainnya (16). Penelitian Campbell, Dworkin, \& Cabral (2009) menunjukkan bahwa dampak perempuan korban tindak kekerasan seksual cenderung mengalami gangguan stress pascatrauma, depresi, bunuh diri, dan terlibat penggunaan narkoba (17). Sedangkan penelitian Johnson, et al. (2008) menemukan bahwa korban kekerasan seksual di Liberia mengalami post traumatic syndrome disorder (PTSD), major depressive disorder (MDD), dan kecenderungan ingin bunuh diri (18). Adapun penelitian Mengo \& Black (2016) yang meneliti kasus kekerasan seksual pada mahasiswa berdampak secara signifikan terhadap kesehatan mental yang mengakibatkan penurunan prestasi akademik (19). Di samping itu, dampak sosial akibat kekerasan seksual yaitu stigmatisasi dan labeling negatif pada si korban dan menjadi stressor yang mempengaruhi terhadap kesehatan mental korban (20).

Namun, tidak semua perempuan yang mengalami tindak kejahatan seksual tersebut berlarut-larut dalam keadaan nestapa. Ada diantara mereka yang mampu bangkit dari keterpurukan, mereka adalah para perempuan penyintas kejahatan seksual. Sebagaimana penelitian Hardjo \& Novita (2017) menunjukkan bahwa dengan adanya dukungan sosial dan psychological well-being, para penyintas kejahatan seksual mampu pulih kembali seperti sedia kala (21). Perempuan penyintas kejahatan seksual yang memiliki perceived helpfulness positif cenderung lebih sehat secara mental (22). Dukungan sosial teman sebaya (23) (23) dan keluarga turut andil dalam mempengaruhi para perempuan korban kekerasan seksual untuk mampu menghadapi kecemasan, depresi, dan pascatrauma (24). Begitu juga penyesuaian psikososial dan upaya meminimalisir penyalahan korban (viktimisasi) dari keluarga mampu mempercepat pemulihan para 
penyintas (25).

Melalui proses penanganan yang intensif dan komprehensif, perempuan korban kekerasan seksual mampu pulih kembali. Penanganan para perempuan korban kekerasan seksual yang dilakukan oleh fasilitator/pendamping di Women's Crisis Center (WCC) Jombang menunjukkan bahwa para perempuan penyintas kekerasan seksual mampu pulih seperti sedia kala (26). Faktor pendukung pulihnya para korban kekerasan seksual melalui proses pemulihan diri adalah dukungan lingkungan, keyakinan agama, dan karakteristik kepribadian (27). Di samping itu, potensi spiritualitas yang dimiliki para penyintas secara signifikan dapat dijadikan modal dalam upaya pemulihan dan penyembuhan akibat kejahatan seksual (28). Dengan pendekatan transformatif, para terapis mampu mengembangkan kesadaran para perempuan penyintas kekerasan seksual menjadi pulih kembali (29). Resiliensi perempuan penyintas kekerasan seksual muncul melalui proses terapiutik sehingga perempuan penyintas mendapatkan harga diri (selfesteem) nya kembali (30).

Berdasarkan latar belakang masalah tersebut, selanjutnya perlu diungkap secara mendalam keadaan psikologis para perempuan penyintas kekerasan seksual. Salah satu keadaan psikologis yang berkaitan dengan proses pemulihan para perempuan penyintas yaitu quality of life (HRQoL). Choi, Wong, \& Fong (2017) meneliti tentang faktor-faktor yang terkait health-related quality of life (HRQoL) pada perempuan penyintas kekerasan seksual menemukan bagaimana para penyintas itu berusaha untuk pulih kembali (31). Perempuan yang mengalami tindak kekerasan seksual rentan terhadap penurunan kualitas hidup (quality of life) (32). Penelitian Soares, Viitasara, \& Macassa, (2007) menunjukkan bahwa quality of life para perempuan korban kekerasan seksual lebih rendah dibandingkan dengan perempuan normal (33). Temuan penelitian Lamoureux-Lamarche \& Vasiliadis (2017) menunjukkan bahwa para perempuan korban kekerasan seksual cenderung mengalami penurunan health-related quality of life (HRQoL) akibat pengalaman traumatik yang berakibat terjadinya penurunan kepuasan hidup (34). Sedangkan menurut Johnson \& Johnson (2013), dengan adanya penanganan yang komprehensif para penyintas mampu menunjukkan quality of life yang lebih baik (18). Adapun hasil penelitian Ajema, Mukoma, Kilonzo, Bwire, \& Otwombe, (2011) menunjukkan bahwa layanan kesehatan yang diberikan kepada para penyintas kejahatan seksual berpengaruh terhadap quality of life (35). Penelitian ini menfokuskan pada bagaimana keadaan quality of life para perempuan penyintas yang sedang mengikuti kegiatan support group di Women's Crisis Center (WCC) Jombang.

\section{Metode Penelitian}

Penelitian ini menggunakan pendekatan kualitatif dengan jenis penelitian studi kasus. Penelitian ini bertujuan untuk mengungkap realitas sosial secara holistic contextual melalui pengumpulan data latar alami dengan memanfaatkan diri peneliti sebagai instrumen kunci. Dengan pendekatan kualitatif, peneliti dapat mengungkap faktor-faktor yang menyebabkan quality of life para penyintas kekerasan seksual. Subyek penelitian ini adalah remaja perempuan penyintas kekerasan seksual peserta dampingan program kegiatan support group yang dilakukan oleh Women's Crisis Center (WCC) Jombang. Subyek penelitian ini adalah para remaja korban kejahatan seksual tindak pemerkosaan dan kekerasan dalam pacaran yang sedang mengikuti pendampingan dan terapi penyembuhan psikologis.

Teknik pengumpulan data dalam penelitian ini menggunakan wawancara dan observasi kualitatif. Teknik wawancara digunakan untuk menggali informasi agar sesuai dengan fokus penelitian ini, sehingga data yang diperoleh sesuai dengan kenyataan atas dinamika yang terjadi. Dengan menggunakan teknik wawancara, data utama yang berupa ucapan, pikiran, perasaan dan tindakan dari subyek diharapkan akan lebih mudah diperoleh. Untuk menghindari bias penelitian, peneliti tetap menggunakan pedoman wawancara namun bersifat fleksibel, sewaktu-waktu dapat berubah sesuai dengan perkembangan data yang terjadi di lapangan. Sedangkan teknik observasi kualitatif digunakan untuk mengamati peristiwa dan perilaku individu dalam setting alami. Saat observasi, peneliti merekam atau mecacat baik dengan cara terstruktur maupun semi struktur dengan menggunakan observasi partisipan yaitu peneliti mengamati langsung sikap yang muncul selama para perempuan penyintas kekerasan seksual peserta dampingan program kegiatan support group yang dilakukan oleh Women's Crisis Center (WCC) Jombang.

Analisis data dilakukan pada saat pengumpulan data dan setelah pengumpulan data. Data yang diperoleh dari lapangan merupakan data mentah diolah supaya didapat suatu data yang siap disajikan menjadi hasil dari suatu penelitian. Dalam melakukan analisis data ini digunakan langkah-langkah sebagai berikut: (1) reduksi data, peneliti mengumpulkan data dan memilah-milah setiap data yang didapat ke dalam bagian-bagian yang memiliki kesamaan; (2) analisis keabsahan data untuk mendapatkan konsistensi data; dan (3) triangulasi data baik melalui triangulasi metode maupun triangulasi sumber/informan yang dilakukan peneliti untuk upaya pengecekan dan pengecekan kembali (checking and rechecking) data, dengan cara menguji kembali temuan data yang berbeda-beda menjadi konklusi yang meyakinkan. 


\section{Hasil Penelitian}

Deskripsi Subyek

Subyek pertama adalah remaja perempuan berumur 16 tahun telah menjadi peserta dampingan program kegiatan support group selama satu tahun di lembaga Women's Crisis Center (WCC) Jombang. Subyek pertama ini menjadi korban tindak kejahatan pemerkosaan yang menyebabkan kehamilan dan telah melahirkan anak berumur 1,5 tahun. Latar belakang keluarga subyek pertama ini dari keluarga tidak mampu secara ekonomi, orang tuanya adalah buruh pabrik dengan penghasilan rata-rata perbulan kurang dari 2 juta rupiah (tergolong keluarga miskin). Sedangkan subyek kedua adalah remaja perempuan berumur 17 tahun yang mengalami trauma psikologis akibat tindak pelecehan seksual yang dilakukan oleh teman laki-lakinya (pacar). Subyek kedua ini juga sama-sama peserta dampingan yang selama setahun telah mengikuti kegiatan pendampingan pada support group di lembaga Women's Crisis Center (WCC) Jombang. Kasus yang dialami oleh subyek kedua ini adalah trauma psikologis akibat penyebaran rekaman pelecehan seksual yang diunggah dan disebarkan melalui media sosial oleh teman laki-lakinya (pacar).

\section{Temuan Penelitian}

Temuan penelitian dideskripsikan sebagaimana fokus penelitian yaitu gambaran kualitas hidup (quality of life) remaja penyintas kekerasan seksual yang mengikuti kegiatan pendampingan pada support group di lembaga Women's Crisis Center (WCC) Jombang. Temuan tentang gambaran kualitas hidup (quality of life) perempuan penyintas kekerasan seksual adalah sebagai berikut:

Kebahagiaan (Happiness)

Gambaran kebahagian (happiness) tampak pada perempuan penyintas yang sudah mulai hilang beban psikologis akibat kekerasan seksual. Mereka merasakan adanya dukungan dari teman-teman yang senasib yang sama-sama mengalami tindakan kekerasan seksual pada saat kegiatan support group. Dukungan sosial keluarga terutama anak dan orang tua serta orang-orang di lingkungan sekitar turut juga memulihkan kembali kondisi para penyintas. Selain dukungan emosional yang diberikan oleh orang-orang terdekat penyintas, juga dukungan instrumental berupa pembiayaan dan akses ekonomi, pemberian peranperan sosial, dan pemberian tanggung jawab kepada penyintas dalam tugas-tugas di tempat pendampingan (WCC) maupun di rumah menjadi faktor penyintas menemukan kebahagiaannya lagi.

Kepuasan Hidup (Life Satisfaction)

Gambaran kepuasan hidup (life satisfaction) pada perempuan penyintas memperoleh kepuasan hidup ketika penyintas mampu terbuka untuk berbagi dan menceritakan masalah yang dihadapi kepada orang yang dipercaya. Melalui kegiatan support group, para penyintas menemukan orang-orang yang mau mendengarkan keluhan serta berbagai ragam masalah yang dihadapi setelah mereka mengalami kekerasan seksual. Penerimaan orang-orang yang ada di sekitar penyintas menjadi awal mereka mampu menemukan kembali kepuasan hidup. Selanjutnya, ketika penyintas yakin akan kemampuan yang dimiliki untuk kembali ke kehidupan seperti sedia kala, di saat itulah penyintas mulai mampu memerankan diri dengan tugas-tugas sosial seperti menjadi seorang ibu, mencari nafkah, dan memberi manfaat kepada orang lain.

Kesejahteraan Hidup (Subjective Well-being)

Gambaran kesejahteraan subyektif (subjective well-being) perempuan penyintas dimulai ketika mereka mampu melupakan kesedihan dan kejadian yang menyakitkan. Usaha yang dilakukan oleh penyintas untuk memulai kehidupan baru dan melupakan kejadian masa lalu adalah dengan cara mengikuti kegiatan "Kejar Paket C" supaya dapat ijazah SMA sebagai modal memulai karier dan bekerja. Munculnya keinginan untuk dapat bekerja secara layak agar mampu menghidupi keluarga merupakan cara penyintas menemukan kesejahteraan subyektif nya (subjective well-being). Para penyintas sudah menemukan kembali makna hidup (meaning of live) melalui rangkaian kegiatan yang intensif di WCC, dan mulai diterimanya mereka di lingkungan keluarga dan masyarakat. Peran lembaga WCC dalam penguatan psikologis penyintas turut memicu kesadaran penyintas menemukan kembali harapan hidup yang lebih baik.

Emosi Positif dan Negatif (Positive and Negative Affect)

Gambaran kemampuan mengelola emosi positif dan negatif (positive and negative affect) perempuan penyintas ditunjukkan dengan merawat dan membesarkan anak agar tumbuh kembang seperti anak-anak dari keluarga pada umumnya. Meski resiko sosial yang dihadapi oleh penyintas cukup berat karena masyarakat sekitar masih memberikan label negatif terhadap anaknya. Kemampuan resilien penyintas saat menghadapi cemoohan masyarakat menunjukkan bahwa penyintas mampu mengelola emosi positif dan negatif (positive and negative affect) dengan baik. Para penyintas mulai mampu menyusun rencana kehidupan kembali seperti membuat usaha ekonomi keluarga, melanjutkan jenjang sekolah, melamar pekerjaan, dan merintis bidang usaha sendiri. Kemampuan mengelola emosi akibat trauma masa lalu ditunjukkan juga oleh penyintas saat kegiatan support group berlangsung. Antusiasme penyintas mengikuti seluruh rangkaian kegiatan memperlihatkan emosi positif, sudah tidak mudah sedih, dan mulai memikirkan hal-hal yang positif di masa depan. 


\section{Pembahasan}

Secara umum temuan penelitian ini menujukkan bahwa para penyintas memiliki quality of life yang baik, hal itu ditunjukan dengan adanya penerimaan diri yang positif. Di samping itu para penyintas merasa telah berkurang rasa kecewa, sudah mulai dapat melupakan masa lalu, sudah mampu mengelola emosi, tidak merasa malu karena pernah menjadi korban kekerasan seksual, serta mulai memiliki keyakinan untuk bisa menjadi pribadi yang lebih baik dibandingkan dengan masa lalunya. Penyintas sudah mulai menerima dirinya yang sekarang, meski berbeda dengan perempuan remaja sebayanya yang bebas bersekolah dan bermain. Penyintas mampu menerima diri untuk mengurus anak dan menjalani tanggung jawab sebagai seorang ibu. Faktor-faktor yang mempengaruhi para penyintas mampu pulih dari trauma dan dampak dari kekerasan seksual selain dukungan keluarga terdekat juga kontribusi penyintas dalam melaksanakan tanggung jawab keluarga, mampu mencari nafkah, dan mampu melaksanakan tugas sebagai ibu yang merawat anak-anak di rumah (36). Dukungan orangtua dan teman-teman dekat serta para fasilitator/pendamping di Women's Crisis Center (WCC) Jombang yang membuat penyintas mampu menerima dirinya yang sekarang. Orang-orang terdekat meyakinkan penyintas untuk tidak mendengarkan apa yang dikatakan oleh masyarakat yang selama ini melabeli negatif kepada penyintas. Dengan dukungan sosial orang-orang terdekat, para penyintas yakin mampu menjalani hidup dengan lebih baik lagi (37).

Individu yang memiliki kualitas hidup (quality of life) yang baik ditunjukkan dengan perasaan bahagia (happiness), menjalani hidup secara puas (life satisfaction), merasakan kesejahteraan subyektif (subjective well-being), dan mampu mengelola emosi positif dan negatif (positive and negative affect) (38). Kebahagiaan (happiness) yang tampak pada para penyintas ditunjukkan dengan partisipasi aktif para penyintas mengikuti kegiatan support group di Women's Crisis Center (WCC) Jombang. Menurut Ferdowsian, Kelly, Burner, Anastario, Gohlke, Mishori, McHale, \& Naimer (2018) bahwa intervensi psikologis dengan menguatkan keyakinan pada si korban untuk mampu bangkit dari keterpurukan, memungkinkan para penyintas mampu cepat pulih (39). Perasaan bahagia muncul karena para penyintas bertemu dengan teman-temannya yang senasib di tempat tersebut. Selain bahagia, beban yang dirasakan karena kasus yang pernah dialami dahulu secara bertahap hilang, karena penyintas merasakan adanya dukungan dari teman-teman yang mengikuti support group. Melalui dukungan sosial teman sebaya, para penyintas saling bercerita dan bercanda dengan teman-temannya selama mengikuti support group. Sebab dukungan sosial yang kuat dari lingkungan terdekat mampu mempengaruhi self-esteem para penyintas (40). Penyintas juga merasa senang karena sama-sama merasa memiliki pengalaman traumatik yang sama. Menurut Jacinto, Turnage, \& Cook (2010), dukungan sosial turut memulihkan para penyintas pada kondisi semula. Dukungan keluarga dan teman-teman dekat berupa kasih sayang dan pengalaman emosi positif yang penyintas dapatkan, sehingga membuat kebahagian (happiness) bagi perempuan penyintas (41).

Peran dukungan sosial dan layanan akses pendampingan intensif bagi perempuan korban kekerasan seksual sangat diperlukan untuk upaya proses pemulihan. Oleh karena itu, diperlukan akses layanan kepada para penyintas agar mereka mampu mengungkapkan apa yang dirasakan oleh penyintas (42). Layanan dukungan emosional dan tatap muka, dukungan teman sebaya, layanan informasi, advokasi dan layanan intervensi intensif di lembaga multi disiplin berupa pelatihan dan layanan konsultasi sangat berpengaruh dalam upaya penyembuhan para penyintas (17). Dukungan psiko-sosial yang terbuka dari masyarakat sebagai model pemulihan yang efektif bagi para penyintas untuk kembali pulih seperti sedia kala. Dukungan sosial juga untuk mengurangi rasa kesunyian para penyintas (43). Sebab melalui layanan pengungkapan diri sebagaimana dalam kegiatan support group di WCC, para penyintas mampu pengungkapan segala permasalahan yang dihadapi.

Kualitas hidup (quality of life) tidak hanya bergantung pada kebahagiaan saja, namun juga bergantung pada apa yang dilakukan seseorang untuk bisa bahagia. Hal-hal yang dilakukan oleh penyintas untuk menjadi bahagia adalah dengan bergaul dan berbagi kasih sayang dengan keluarga. Kebahagiaan psikologis merupakan keadaan pikiran, perasaan senang, tenang, dan penuh kasih sayang. Sebab kualitas hidup tidak bergantung pada kebahagiaan saja, tapi juga pada apa yang dilakukan seseorang untuk menjadi bahagia. Para penyintas sangat senang mengikuti kegiatan support group di WCC, karena adanya kegiatan support group ini membuat penyintas lebih percaya diri. Dengan pendekatan transformatif yang berbasis pada individu, perempuan penyintas mampu secara mandiri mengupayakan upaya pemulihan diri untuk melangsungan kehidupan yang lebih baik (44). Hal-hal yang dilakukan oleh para penyintas untuk bahagia adalah dengan memikirkan masa depan dan tidak memikirkan kejadian masa lalu, serta dengan lebih giat belajar agar prestasinya meningkat.

Selain kebahagiaan (happiness) orang yang kualitas hidupnya (quality of life) baik juga memiliki kepuasan hidup (life satisfaction). Kepuasan hidup sebagai sebuah proses penilaian kognitif bergantung pada perbandingan kemampuan keadaan seseorang dengan apa yang dianggap sebagai standar yang sesuai. Penyintas menilai kepuasan hidup (life satisfactin) sebagai perasaan yang tenang, yang tidak ada 
masalah. Hidup yang memuaskan adalah hidup yang tidak membuat terus menerus dirundung kesedihan dan depresi. Hidup yang membahagiakan, menyenangkan, juga saling mendukung dalam keluarga. Para perempuan penyintas kejahatan seksual yang pulih dan kembali ke keluarga adalah mereka yang mendapatkan intervensi yang komprehenshif melalui terapi, rehabilitasi dan reintegrasi sosial dengan lingkungan (45).

Selanjutnya, aspek kualitas hidup (quality of life) lainnya adalah kesejahteraan subyektif (subjective well-being). Kesejahteraan subyektif adalah keadaan afektif abadi (jangka panjang) yang meliputi perasaan sukacita, kasih sayang, kebanggaan, dan lain-lain. Kesejahteraan subyektif (subjective well-being) terlihat dari penuturan penyintas tentang kejadian hamil di luar nikah dan tidak adanya tanggung jawab dari pelaku, membuat penyintas merasa kecewa, malu dan bersalah. Selain itu, penyintas juga mendapatkan cacian dari masyarakat terutama terkait status anak yang di luar pernikahan. Sebab hambatan yang sering dialami oleh para perempuan penyintas kejahatan seksual adalah penyalahan (viktimisasi) terhadap korban, ketidakadilan sistem peradilan, dan layanan medis dan intervensi pendampingan kesehatan mental (46). Namun, berkat dukungan keluarga berupa kasih sayang dari kedua orangtua penyintas, hal ini membuat kulaitas hidup (quality of life) penyintas menjadi lebih baik lagi setelah kejadian yang dialami di masa lalu. Perhatian, kasih sayang, kepedulian yang diberikan orang tua penyintas menjadi pengaruh positif bagi pulihnya kualitas hidup (quality of life) penyintas.

Perempuan korban kejahatan seksual memiliki kecenderungan terjadi penurunan kualitas hidup (quality of life). Penelitian Surís, Lind, Kashner, \& Borman, (2007) menunjukkan bahwa perempuan veteran korban kekerasan seksual memiliki quality of life jauh lebih buruk dibandingkan dengan perempuan yang tidak memiliki riwayat kekerasan seksual (47). Resiko akibat tindakan kekerasan seksual terhadap penurunan quality of life seperti penggunaan alkohol secara berlebihan dan penyiksaan diri (48). Dampak psiklogis lainnya adalah citra diri yang negatif, penurunan fungsi seksual, dan perubahan quality of life yang menurun (49). Para perempuan penyintas kejahatan seksual sering merasa trauma pada saat mendapatkan layanan medis di rumah sakit. Program intervensi seperti sexual assault nurse examiners (SANEs) yang "memanusiakan" kepada para penyintas cenderung lebih menguatkan kesehatan mental para penyintas (50). Banyak perempuan penyintas yang kurang perhatian terhadap kesehatan medis maupun mental, maka perlu promosi akses perawatan medis dan fasilitasi intervensi kesehatan mental (51).

Kesejahteraan subyektif (subjective well-being) juga ditunjukkan oleh penyintas yang pada awalnya merasakan malu dan takut karena kejadian yang sangat menyakitkan. Namun setelah mengikuti kegiatan support group di WCC, dan penyintas dapat bersosialisasi dengan teman-teman yang senasib yang akhirnya membuat mereka mampu beradaptasi. Para penyintas di tempat pendampingan (WCC) merasa memiliki banyak saudara, merasa mampu untuk terbuka berbagi perasaan dan saling bercerita. Ketika para penyintas mengikuti kegiatan support group, mereka luluasa berbagi perasaan dengan teman sebaya dan pendamping, mereka juga mampu mengekspresikan segala beban emosional yang selama ini terpendam. Sebagaimana hasil penelitian Maslihah (2013) menunjukkan bahwa para penyintas kekerasan seksual mampu mengekspresikan perasaan marah sehingga terlampiaskan segala perasaan (52). Sedangkan menurut Sisca \& Moningka (2008) bahwa dukungan sosial sekitar dan potensi-potensi spiritualitas serta religiusitas yang dimiliki oleh para perempuan penyintas sebagai modal untuk resilien (11). Melalui kegiatan yang intensif di WCC, para penyintas mampu bersosialisasi dengan lingkungan sekitar dan mengubah pandangan tentang status korban. Oleh karena itu diperlukan adanya kebijakan dari berbagai pihak tentang penanganan psikososial terhadap korban kekerasan seksual, tidak hanya pada individu korban tetapi juga mengubah cara pandang masyarakat tentang kekerasan seksual dan dampaknya (48).

Masalah kejahatan seksual tidak hanya permasalahan individu tetapi merupakan masalah publik, di mana model penyelesainnya juga berbasis pada permasalahan publik, tidak semata-mata menyelesaikan masalah individu si korban (53). Sebab selama ini pandangan umum masyarakat terutama kaum laki-laki cenderung menyalahkan korban (54). Pemulihan perempuan penyintas kejahatan seksual, reaksi pihak laki-laki terhadap perempuan korban kejahatan seksual sangat mempengaruhi pemulihan korban. Layanan yang tidak berfokus pada penyintas kejahatan seksual, tetapi juga kepada anggota keluarga, karena dukungan keluarga turut membantu terhadap pemulihan korban (36). Oleh karena itu diperlukan upaya pemberdayaan perempuan korban kekerasan seksual supaya meningkat kualitas hidup (quality of life) mereka dan perlu membantu menghilangkan dampak traumatik dan dampak psikologis lainnya (32).

Aspek terakhir dari kualitas hidup (quality of life) adalah emosi positif dan emosi negatif (positive and negative affect). Individu yang mempunyai kualitas hidup yang tinggi apabila emosi positif (seperti kegembiraan, kesenangan atau kebahagiaan) lebih besar dibandingkan emosi negatifnya (seperti kesedihan, depresi, kecemasan dan kemarahan). Penyintas mampu bangkit dan melupakan masa lalu yang menyedihkan, dan ingin lebih fokus mengejar cita-cita dan keinginan yang mampu membahagiakan banyak orang. Sebagaimana yang diungkapkan oleh Zebrack, (2000), bahwa kemampuan menjalankan peran sosial dan tanggung jawab diri baik di keluarga maupun sosial turut berkontribusi dalam meningkatan quality of life para perempuan penyintas kekerasan seksual (55). 


\section{Simpulan dan Saran}

Berdasarkan pembahasan hasil penelitian tersebut di atas, maka dapat disimpulkan bahwa para perempuan penyintas kekerasan seksual memiliki kualitas hidup (quality of life) yang tinggi. Hal ini terlihat dari para penyintas sudah bahagia dan melupakan kejadian yang lalu, penyintas juga puas dengan kehidupan yang dijalani sekarang. Selain itu, pengalaman negatif ataupun pengalaman positif yang dialami oleh penyintas, telah membuat penyintas merasakan kesejahteraan hidup. Emosi positif yang ditunjukkan oleh penyintas lebih banyak daripada emosi negatif yang penyintas rasakan, membuat penyintas merasakan kualitas hidup yang sebenarnya. Selanjutnya, melalui kegiatan support group di Women's Crisis Center (WCC) Jombang yang telah diikuti selama satu tahun terkahir juga memberikan banyak manfaat bagi penyintas. Penyintas menjadi lebih terbuka dan berani menunjukkan diri kepada teman-teman yang senasib di tempat kegiatan tersebut (WCC). Selain itu, dukungan keluarga juga sangat berpengaruh bagi kualitas hidup penyintas. Penyintas memiliki orangtua yang sangat mendukung, membuat penyintas menjadi pribadi yang terlihat bahagia dan mampu menjalani kehidupan yang lebih baik.

Berdasarkan hasil penelitian ini maka dapat diberikan rekomendasi/saran: pertama kepada para perempuan penyintas kekerasan seksual untuk selalu menggunakan potensi dan aset yang dimiliki untuk meningkatkan kualitas hidup (quality of life); kedua kepada lembaga Women's Crisis Center (WCC) supaya tetap konsisten memberikan pelayanan berupa support group terhadap para penyintas kekerasan seksual; dan ketiga kepada peneliti selanjutnya untuk melakukan penelitian dengan metode penelitian lainnya seperti penelitian tindakan, penelitian eksperimen atau penelitian survei dengan subyek dan populasi sampel yang lebih luas.

\section{Daftar Pustaka}

1. Noviani UZ, Arifah R, Cecep, Humaedi S. Mengatasi dan mencegah tindak kekerasan seksual pada perempuan dengan pelatihan asertif. Jurnal Penelitian \& PPM. 2018;5(1):1-110.

2. Setyawan I. Hukuman Bagi Pelaku Kejahatan Seksual Pada Anak Menurut Undang-Undang No. 23 Tahun 2002 Tentang Perlindungan Anak. Kultura. 2015;16(1):4845-4849.

3. Sumera M. Perbuatan Kekerasan/Pelecehan Seksual Terhadap Perempuan. Lex et. Societatis. 2013;2:3949.

4. Nafisah S. Penanganan Perempuan Korban Kekerasan Seksual Di PPT Seruni Kota Semarang. Jurnal SAWWA. 2016;11:211-228.

5. Dzuhayatin SR, Yuarsi SE. Ringkasan hasil penelitian kekerasan terhadap perempuan di ruang publik. Yogyakarta: PSKK UGM dan Ford Foundation. 2002.

6. Perempuan K. Lembar Fakta Catatan Tahunan (CATAHU) Komnas Perempuan Tahun 2017. Lembar Fakta Catatan Tahunan (CATAHU) Komnas Perempuan. In: Siaran Pers/Lembar Fakta Catahu 2017.pdf [Internet]. 2017. Available from: https://www.komnasperempuan.go.id/file/pdf_file/2017

7. Sunarto H, Faiqoh LSWS. Pelecehan Seksual: Maskulinisasi Identitas Pada Mahasiswi Jurusan Teknik Elektro Undip. Interaksi Online. 2013;10-1007.

8. Musarrofa I. Mekanisme Kekerasan terhadap Perempuan dalam Rumah Tangga Perspektif Teori Kekerasan Simbolik Pierre Bourdieu. Asy-Syir'ah. 2015;49(2):458-470.

9. Shields RT, Feder KA. The public health approach to preventing sexual violence. In: Sexual Violence: Evidence Based Policy and Prevention. Springer International Publishing; 2016. p. (pp. 129-144).

10. Souza FBC, Drezett J, Meirelles ADC, Ramos DG. Psychological aspects of women who suffer sexual violence. Reproducao e Climaterio. 2012;27(3):98-103.

11. Sisca H, Moningka C. Resiliensi Perempuan Dewasa Muda yang Pernah Mengalami Kekerasan Seksual di Masa Kanak-Kanak. Jurnal Psikologi. 2008;2(1):61-69.

12. Nurhayati D. Dampak psikologis tindak pidana kekerasan seksual terhadap perempuan. Perspektif. 2007;12(3):269-281.

13. De Moraes SDT, Da Fonseca AM, Bagnoli VR, Soares Júnior JM, De Moraes EM, Das Neves EM, et al. Impact of domestic and sexual violence on women's health. Journal of Human Growth and Development. 2012;22(2):253-258.

14. Chisholm CA, Bullock L, Ferguson JE. Intimate partner violence and pregnancy: epidemiology and impact. American Journal of Obstetrics and Gynecology. 2017;217(2):141-144.

15. Bell KA. Victims' voices: Sexual violence in the Armenian and Rwandan genocides. ProQuest Dissertations and Theses. Northeastern University [Internet]. 2015. Available from: http://ezproxy.library.yorku.ca.

16. Basile KC, Smith SG. Sexual Violence Victimization of Women. American Journal of Lifestyle Medicine. 2011;5(5):407-417.

17. Campbell L. Sexual Assault Support Service for Canterbury Research to Inform Service Design. Family Violence Services. 2016. 1-365 p. 
18. Johnson R, Johnson G. Survivorship and quality of life. The Neuropsychology of Cancer and Oncology. 2013. 425-439 p.

19. Mengo C, Black BM. Violence Victimization on a College Campus: Impact on GPA and School Dropout. Journal of College Student Retention: Research, Theory and Practice. 2016;18(2):234-248.

20. Verelst A, De Schryver M, Broekaert E, Derluyn I. Mental health of victims of sexual violence in eastern Congo: Associations with daily stressors, stigma, and labeling. BMC Women's Health. 2014;14(1):1-12.

21. Hardjo S, Novita E. Hubungan dukungan sosial dengan psychological well-being pada remaja korban sexual abuse. ANALITIKA. 2017;7(1):12-19.

22. Starzynski LL, Ullman SE. Correlates of Perceived Helpfulness of Mental Health Professionals Following Disclosure of Sexual Assault. Violence Against Women. 2014;20(1):74-94.

23. Banyard VL, Moynihan MM, Walsh WA, Cohn ES, Ward S. Friends of Survivors. Journal of Interpersonal Violence. 2010;25(2):242-256.

24. Illanes V, E. B, M L, Vizcarra L, B. M, Munoz N, et al. Social and familial determinants of anxiety and depressive symptoms in middle to low income women. REVISTA MEDICA DE CHILE. 2007;135(3):326-334.

25. Sigurvinsdottir R, Ullman SE. Sexual Orientation, Race, and Trauma as Predictors of Sexual Assault Recovery Sexual Assault Victimization and Recovery of Sexual Minorities. Journal of Family Violence. 2016;31(7):913-921.

26. Harmoni Y. Data Kasus Kekerasan terhadap Perempuan 2018 [Internet]. 2018. Available from: http://www.wccjombang.org/2018/02/data-kasus-kekerasan-terhadap-perempuan.html.

27. Illenia PS, Hendadari W. Pemulihan Diri pada Korban Kekerasan Seksual. INSAN. 2011;13(2):118-128.

28. Knapik GP, Martsolf DS, Draucker CB. Being delivered: Spirituality in survivors of sexual violence. In: Issues in Mental Health Nursing. 2008. p. 335-350.

29. Garrity MK. Counselling Sexual-Violence Survivors: The Evolution of Female Counsellors' Critical Political Consciousness and the Effects on Their Intimate Relationships. Canadian Journal of Counselling and Psychotherapy. 2011;45(1):68-86.

30. Miyatsu T, Koyano Y, Ishibashi K. Resilience beyond a life of living death: A qualitative analysis of narratives by sexual violence survivors. In: Japan Early Intervention in Psychiatry, 10 [Internet]. 2016. p. 217. Available from: https://doi.org/10.1111/eip.12397.

31. Choi EPH, Wong JY, H., Fong DYT. Mental health and the health-related quality of life of college students suffering from sexual dating violence. Journal of Sexual Medicine [Internet]. 2017;14(5). Available from: http://ovidsp.ovid.com/ovidweb.cgi

32. Asadi S, Mirghafourvand M, Yavarikia P, Mohammad-Alizadeh-Charandabi S, Nikan F. Domestic Violence and its Relationship with Quality of Life in Iranian Women of Reproductive Age. Journal of Family Violence. 2017;32(4):453-460.

33. Soares JJF, Viitasara E, Macassa G. Quality of life among lifetime victimized men. Violence and Victims [Internet]. Springer Publishing; 2007. Available from: https://doi.org/10.1891/088667007780477366.

34. Lamoureux-Lamarche C, Vasiliadis HM. Lifetime traumatic events, health-related quality of life, and satisfaction with life in older adults. Quality of Life Research. 2017;26(10):2683-2692.

35. Ajema C, Mukoma W, Kilonzo N, Bwire B, Otwombe K. Challenges experienced by service providers in the delivery of medico-legal services to survivors of sexual violence in Kenya. Journal of Forensic and Legal Medicine. 2011;18(4):162-166.

36. Kelly J, Albutt K, Kabanga J, Anderson K, VanRooyen M. Rejection, acceptance and the spectrum between: Understanding male attitudes and experiences towards conflict-related sexual violence in eastern Democratic Republic of Congo. BMC Women's Health. 2017;17(1):10-1186.

37. O'Callaghan E, Lorenz K, Ullman SE, Kirkner A. A Dyadic Study of Impacts of Sexual Assault Disclosure on Survivors'. Informal Support Relationships Journal of Interpersonal [Internet]. 2018; Available from: https://doi.org/10.1177/0886260518795506.

38. Sirgy MJ. The Psychology of Quality of Life. The Psychology of Quality of Life (Vol. 2002;50:417-437.

39. Ferdowsian H, Kelly S, Burner M, Anastario M, Gohlke G, Mishori R, et al. Attitudes toward Sexual Violence Survivors: Differences across Professional Sectors in Kenya and the Democratic Republic of. the Congo Journal of Interpersonal Violence. 2018;33(24):3732-3748.

40. Orchowski LM, Untied AS, Gidycz CA. Social Reactions to Disclosure of Sexual Victimization and Adjustment among Survivors of Sexual Assault. Journal of Interpersonal Violence. 2013;28(10):20052023.

41. Jacinto GA, Turnage BF, Cook I. Domestic violence survivors: Spirituality and social support. Journal of Religion and Spirituality in Social Work. 2010;29(2):109-123.

42. Bogen KW, Leach NR, Meza Lopez RJ, Orchowski LM. Supporting students in responding to disclosure of sexual violence: a systematic review of online university resources. Journal of Sexual Aggression Routledge [Internet]. 2018; Available from: https://doi.org/10.1080/13552600.2018.1509576.

43. Edström J, Dolan C. Breaking the Spell of Silence: Collective Healing as Activism amongst Refugee Male Survivors of Sexual Violence in Uganda. Journal of Refugee Studies. 2018;1(22):10-1093. 
44. Rowntree M. "Living life with grace is my revenge": Situating survivor knowledge about sexual violence. Qualitative Social Work. 2010;9(4):447-460.

45. Crawford M, Kaufman MR. Sex trafficking in Nepal: Survivor characteristics and long-term outcomes. Violence Against Women. 2008;14(8):905-916.

46. Ullman SE, Townsend SM. Barriers to Working with Sexual Assault Survivors. Violence Against Women. 2007;13(4):412-443.

47. Surís A, Lind L, Kashner TM, Borman PD. Mental health, quality of life, and health functioning in women veterans differential outcomes associated with military and civilian sexual assault. Journal of Interpersonal Violence. 2007;22(2):179-197.

48. Sahin B, Dundar P. Violence against women and quality of life. Anatolian Journal of Psychiatry [Internet]. 2017;1. Available from: https://doi.org/10.5455/apd.246081.

49. Lee Y, Lim MC, Kim SI, Joo J. Quality of life and sexual function in cervical cancer survivors compared to healthy women. International Journal of Gynecological Cancer. 2014;24(9):812.

50. Fehler-Cabral G, Campbell R, Patterson D. Adult sexual assault survivors' experiences with sexual assault nurse examiners (SANES). Journal of Interpersonal Violence. 2011;26(18):3618-3639.

51. Bartels SA, Scott JA, Leaning J, Kelly JTD. Demographics and care-seeking behaviors of sexual violence survivors in South Kivu Province, Democratic Republic of Congo. Disaster Medicine and Public Health Preparedness American Medical Association [Internet]. 2012;515. Available from: https://doi.org/http

52. Maslihah S. Play Therapy dalam Identifikasi Kasus Kekerasan Seksual terhadap Anak. Jurnal Penelitian Psikologi. 2013;4(1):21-34.

53. Muldoon SD, Taylor SC, Norma C. The Survivor Master Narrative in Sexual Assault. Violence Against Women. 2016;22(5):565-587.

54. Clarke AK, Stermac L. The Influence of Stereotypical Beliefs, Participant Gender, and Survivor Weight on Sexua Assault Response. Journal of Interpersonal Violence [Internet]. 2011; Available from: https://doi.org/10.1177/0886260510383039.

55. Zebrack BJ. Cancer survivor identity and quality of life. Cancer Practice. 2000;8(5):238-242. 